\title{
AUTOAVALIAÇÃO COMO RECURSO FORMATIVO E FORMADOR: DA EDUCAÇÃO SUPERIOR AO CONTEXTO ESCOLAR
}

\author{
Ivone Maria Mendes Silva (UFFS)* \\ https://orcid.org/0000-0002-0058-091X \\ Aline Paula Pochmann Bordin (UFFS)** \\ https://orcid.org/0000-0001-6905-3731 \\ Altair Alberto Fávero (UPF)*** \\ https://orcid.org/0000-0002-9187-7283
}

\section{RESUMO}

Este artigo discute a importância dos processos de autoavaliação e de reflexão que podem se fazer presentes na formação e atuação docente. Problematiza ainda o papel da educação superior no trabalho com o tema no contexto da formação inicial e continuada de professores, bem como no enfrentamento dos desafios de se consolidar como espaço de construção de saberes indispensáveis à profissionalização docente. Para tanto, foi realizada pesquisa, de natureza qualitativa, envolvendo estudos bibliográficos e de campo, os quais apontaram que os docentes pesquisados não estão tendo acesso a experiências formativas que lhes inspirem e ensinem a incorporar a autoavaliação às suas práticas profissionais cotidianas ou mesmo a significá-la como um recurso valioso para o trabalho educativo. Conclui-se que há lacunas na formação inicial e continuada dos profissionais da educação no que tange à abordagem da autoavaliação e também da avaliação, corroborando resultados de outras pesquisas.

Palavras-chave: Autoavaliação. Reflexão. Formação de professores. Educação superior. Escola.

\section{ABSTRACT}

\section{SELF-EVALUATION AS A FORMATIVE AND FORMATION RESOURCE: FROM HIGHER EDUCATION TO SCHOOL CONTEXT}

This article discusses the importance of the processes of self-evaluation and reflection present in the formation and teaching performance. It also problematizes the role of higher education in working with the subject in the context of initial and continuing teacher education, as well as addressing

Doutora em Psicologia pela Universidade de São Paulo (USP). Professora adjunta da Universidade Federal da Fronteira Sul (UFFS) - Campus Erechim/RS. E-mail: ivonemmds@gmail.com

** Mestra em Educação pela Universidade Federal da Fronteira Sul (UFFS) - Campus Erechim/RS. E-mail: alinebrdn@gmail.com

*** Pós-Doutor em Docência Universitária pela Universidad Autónoma del Estado de México (UAEMéx). Doutor em Educação pela Universidade Federal do Rio Grande do Sul (UFRGS). Professor titular da Universidade de Passo Fundo (UPF). E-mail: altairfavero@gmail.com 
the challenges of consolidating as a space for building knowledge that is indispensable for teacher professionalization. To that end, a qualitative research was carried out, involving bibliographical and field studies, which pointed out that the teachers studied are not having access to formative experiences that inspire them and teach them to incorporate self-assessment into their daily professional practices or even the meaning it as a valuable resource for educational work. It is concluded that there are gaps in the initial and continuous training of education professionals regarding the approach of self-assessment and also of evaluation, corroborating the results of other researches.

Keywords: Self-evaluation. Reflection. Teacher education. Higher education. School.

\section{RESUMEN}

\section{AUTOEVALUACIÓN COMO RECURSO FORMATIVO Y DE FORMACIÓN: DE LA EDUCACIÓN SUPERIOR AL CONTEXTO ESCOLAR}

Este artículo discute la importancia de los procesos de autoevaluación y de reflexión que pueden hacerse presentes en la formación y actuación docente. Y en el contexto de la formación inicial y continuada de profesores, así como en el enfrentamiento de los desafíos de consolidarse como espacio de construcción de saberes indispensables para la profesionalización docente. Para ello, se realizó investigación, de naturaleza cualitativa, involucrando estudios bibliográficos y de campo, los cuales apunta que los docentes encuestados no están teniendo acceso a experiencias formativas que les inspire y enseña a incorporar la autoevaluación a sus prácticas profesionales cotidianas o incluso a la significante como un recurso valioso para el trabajo educativo.Se concluye que hay lagunas en la formación inicial y continuada de los profesionales de la educación en lo que se refiere al abordaje de la autoevaluación y también de la evaluación, corroborando los resultados de otras investigaciones.

Palabras clave: Autoevaluación. Reflexión. Formación de profesores. Educación superior. Escuela.

\section{Introdução}

Verbos como revisitar, reconhecer, repensar, e muitos outros similares a esses, são utilizados constantemente, mesmo que de forma inconsciente, em nossas vidas pessoais e profissionais, para pontuar processos complexos que marcam a relação que estabelecemos com a dinamicidade do real e as possibilidades do agir humano sobre ele. Na família, na comunidade, no trabalho, nos espaços de formação, o ser humano pode ser surpreendido com situações delicadas, de difícil resolução, que exigem a reflexão sobre valores, interesses e concepções, assim como a avaliação crítica de atitudes assumidas diante de circunstâncias e acontecimentos.

Na área da educação, verbos como esses são conhecidos e utilizados com frequência pelos professores e demais atores inseridos nesse campo. Isso porque o conhecimento não é algo estático, mas uma construção, derivada de processos que surgem na relação entre pessoas, saberes e experiências diversas. E, nesse cenário, o trabalho educativo certamente coloca desafios cotidianos, aos quais é preciso reagir 
produzindo compreensões e posicionamentos baseados na avaliação constante dos sujeitos e suas ações, bem como dos contextos (próximos e distais) com os quais estas se relacionam.

Neste artigo, discutimos a importância dos processos de autoavaliação e de reflexão que podem se fazer presentes na formação e atuação docente. Para tanto, realizamos pesquisa empírica ${ }^{1}$ com professores e outros profissionais da educação sobre o tema. Além disso, buscamos construir uma discussão teóricoconceitual que pretende situar tais conceitos, problematizando a concepção de "professor reflexivo", tão difundida no contexto educacional brasileiro. Nossa intenção é identificar as possibilidades e limites associados ao uso desses conceitos e suas implicações para a prática educativa, visualizando a sua pertinência na área educacional, tanto para professores como para estudantes, nos diferentes níveis de ensino, ou seja, desde a educação básica até o ensino superior.

Para empreender a discussão sobre as especificidades da autoavaliação enquanto processo de reflexão, foram utilizadas as contribuições de Manuela Terrasêca, John MacBeath e outros autores. Para problematizar o conceito de reflexão, recorremos aos apontamentos feitos por Selma Garrido Pimenta, que discute a concepção de professor reflexivo utilizada por Donal Schön, abordando as críticas que podem ser tecidas à concepção de reflexão defendida pelo autor. Além de comentar as aproximações e contrastes possíveis de serem identificados em diferentes perspectivas existentes sobre essa temática na literatura nacional, buscamos trazer para o debate as considerações propostas pelo autor americano Kenneth Zeichner, que alimenta a discussão com outros apontamentos pertinentes. Além de buscar fundamentação teórica nas obras dos autores supracitados,

1 Na consecução da pesquisa empírica, foram adotados diversos cuidados éticos, entre eles a promoção de momentos de diálogo com os participantes sobre os objetivos da pesquisa e outras questões. Também foram empregados termos de consentimento livre e esclarecido, com garantia de anonimato aos participantes. utilizamos análises provindas de pesquisas recentes realizadas por outros pesquisadores sobre os assuntos que são objeto de nossa investigação, numa tentativa de produzir avanços na análise do tema utilizando múltiplas fontes.

0 percurso trilhado ao construir essa discussão permitiu-nos constatar a relevância da autoavaliação para os processos educativos e o quanto esse recurso pode ser determinante no êxito profissional dos professores e, consequentemente, na geração de efeitos positivos para a sociedade como um todo. Não obstante, esse profissional deve estar atento a como e quando realizar a autoavaliação, que aspectos priorizar e com que finalidade, observando o lugar assumido pela reflexão no processo. Essas e outras questões precisam ser abordadas desde a formação inicial do professor, que deve ser instigado e preparado para realizar a autoavaliação-reflexão de sua prática. 0 sucesso ou não dessa ação tem relação direta com a maneira como ela é compreendida e efetivada, como foi ou poderá ser aprendida ao longo da formação inicial e continuada.

Nesse sentido, o presente artigo apresenta-se estruturado em cinco seções. Após essa seção introdutória, apresentamos a metodológica, na qual detalhamos como se realizaram o estudo bibliográfico e a pesquisa empírica que facultaram a discussão aqui produzida. Nas terceira e quarta seções, são definidos conceitos e expostas as perspectivas de alguns autores para fundamentar a nossa análise do tema. A quinta seção traz a discussão empreendida a partir dos resultados da pesquisa empírica que realizamos junto a professores e outros profissionais da educação. Por fim, a sexta e última seção contempla as considerações finais.

\section{Método}

As análises apresentadas neste artigo estão embasadas em pesquisa qualitativa, de caráter exploratório-descritivo, que teve como objetivo central possibilitar maior conhecimento acerca das concepções sustentadas por docentes e ou- 
tros profissionais da educação no que tange aos processos de autoavaliação e reflexão, além da problematização desses dados a partir de discussão teórico-conceitual fundamentada nas contribuições de diferentes estudiosos da área.

Assim como Gil (2008, p. 26), compreendemos a pesquisa como "o processo formal e sistemático de desenvolvimento do método científico", que visa elucidar, por meio de procedimentos pertinentes, questões ou problemas identificados pelo pesquisador. Em relação às pesquisas exploratórias, é possível afirmar que elas possibilitam "desenvolver, esclarecer e modificar conceitos e ideias, tendo em vista a formulação de problemas mais precisos ou hipóteses pesquisáveis para estudos posteriores" (GIL, 2008, p. 27), ou seja, avançar gradualmente na familiarização com o objeto pesquisado e, a partir disso, produzir avanços na teorização sobre ele. Uma estratégia que tem se mostrado pertinente especialmente no estudo de temas pouco explorados na literatura científica, como é o caso dos processos de autoavaliação no contexto educacional.

Para alcançarmos os objetivos propostos para o estudo, realizamos pesquisa bibliográfica, efetivada em diversas etapas (anteriores e posteriores à produção de dados empíricos), e pesquisa de campo, com emprego de questionários.

A seleção do material utilizado na pesquisa bibliográfica teve como base a aplicação dos critérios temático, linguístico, cronológico e tipo de fonte consultada, conforme definidos por Lima e Mioto (2007). 0 "parâmetro temático" refere-se ao acesso a materiais bibliográficos correlacionados ao tema abordado, que na presente pesquisa refere-se aos processos de autoavaliação em sua relação com as discussões sobre reflexão (professor reflexivo, prática reflexiva etc.). Já o "parâmetro linguístico" diz respeito ao idioma dos materiais analisados, sendo o português a língua aqui escolhida. 0 terceiro parâmetro é a "seleção das fontes" a serem consultadas, sendo as utilizadas neste estudo os artigos publicados em periódicos in- dexados, bem como livros, dissertações e teses acessíveis na Internet ou no acervo pessoal dos autores deste artigo. E, por último, atentamos para o "parâmetro cronológico" das obras visadas, buscando priorizar a análise daquelas publicadas ao longo das últimas duas décadas, sem, contudo, excluir a possibilidade de uso de publicações anteriores a esse período, uma vez que contribuições importantes à tematização sobre autoavaliação e reflexão na formação docente puderam ser nelas identificadas (LIMA; MIOT0, 2007, p. 41).

Como parte da pesquisa empírica, desenvolvida no ano de 2019 , foi aplicado um questionário contendo, dentre outras perguntas, uma que englobava pontos atinentes à autoavaliação e à formação recebida sobre o assunto pelos participantes da pesquisa, a qual reproduzimos na sequencia: "Na sua formação inicial e/ ou continuada, você teve contato com o tema autoavaliação ou com algum conteúdo que se aproximasse do assunto? Como?"

Esse questionário foi aplicado a cinco professores atuantes em diferentes níveis e instituições de ensino do noroeste do estado do Rio Grande do Sul. Também participaram da pesquisa cinco coordenadores pedagógicos que trabalham nas escolas onde os docentes acima referidos estão inseridos, junto aos quais buscou-se averiguar qual o posicionamento das instituições onde atuam face à efetivação/ motivação da prática da autoavaliação.

Ainda sobre os dez participantes da pesquisa, cabe mencionar que dois deles atuam numa instituição particular de ensino, e os demais na rede pública. Quanto aos professores, três têm formação em Pedagogia, um em Educação Física e outro em Filosofia. Entre os coordenadores pedagógicos, dois são graduados em História, dois em Pedagogia e um em Artes Visuais. Alguns desses profissionais concluíram suas graduações em universidades públicas e outros frequentaram instituições particulares.

Para análise dos dados obtidos, inspiramonos nos pressupostos da análise de conteúdo 
segundo método proposto por Bardin (2010, p. 40), que a define como um "conjunto de técnicas de análise das comunicações que utiliza procedimentos sistemáticos e objetivos de descrição do conteúdo das mensagens". Com base nesses pressupostos, foram empreendidas algumas leituras do material obtido com a aplicação dos questionários, facultando a produção de inferências, num processo alimentado pelo diálogo com a literatura científica revisada durante a pesquisa bibliográfica. Posteriormente, procedeu-se com a organização dos achados derivados dessa primeira exploração do material em eixos temáticos mais amplos, partindo-se, na sequencia, para a análise mais aprofundada do material. Esta considerou a existência de recorrências/semelhanças e divergências/contrastes nos conteúdos analisados, buscando relacioná-los aos apontamentos feitos pelos autores que serviram de fundamentação teórica ao estudo e também os achados de outras pesquisas já realizadas sobre o mesmo tema. Esses foram os procedimentos e critérios seguidos para a consecução da análise dos dados obtidos na pesquisa.

\section{Formação docente e autoavaliação}

A formação inicial e continuada de professores é vista, na atualidade, como um dos temas cruciais da educação. De maneira sucinta e direta, Veiga (2008, p. 15) descreve o significado do termo formação docente: "A formação de professores constitui o ato de formar o docente, educar o futuro profissional para o exercício do magistério. Envolve uma ação a ser desenvolvida com alguém que vai desempenhar a tarefa de educar, de ensinar, de aprender, de pesquisar e de avaliar".

Contudo, essa autora não restringe a formação docente a esse breve conceito formal. Utilizando diferentes autores para melhor compreensão dessa prática, Veiga (2008), na obra Profissão docente: novos sentidos, novas perspectivas, ao resgatar o conceito de forma- ção docente como fundamental na atuação do professor atualmente - profissional este que se depara constantemente com mudanças -, complementa-o, apontando que o termo formação evidencia uma ação em construção, "o processo de formação é multifacetado, plural, tem início e nunca tem fim" (VEIGA, 2008, p. 15).

A formação inicial de professores é imprescindível e merece atenção dos órgãos responsáveis por sua promoção. Ao conceber esta formação como uma ação contínua, na qual o professor precisa acompanhar as transformações da sociedade, pois estas refletem diretamente na escola, cabe ao professor se atualizar, buscar novos conhecimentos, se formar constantemente, visto que os estudantes, sujeitos sociais, carecem desta versatilidade docente.

Diante do exposto, fica evidenciada a necessidade e importância da formação contínua. 0 professor é um profissional que carece de formação durante todo o exercício de sua profissão, pois o seu objeto de trabalho permanece em constante transformação.

García (1999, p. 22), autor que também detém vasto conhecimento nessa área, discorre que "a formação de professores representa um encontro entre pessoas adultas, uma interacção entre formador e formando, com uma intenção de mudança, desenvolvida num contexto organizado e institucional mais ou menos delimitado".

Complementando essa breve definição, García (1999, p. 26) descreve o processo de formação de professores com as seguintes palavras:

A Formação de Professores é a área de conhecimentos, investigações e de propostas teóricas e práticas que, no âmbito da Didática e da Organização Escolar, estuda os processos através dos quais os professores - em formação ou em exercício - se implicam ou em equipa, em experiências de aprendizagem através dos quais adquirem ou melhoram os seus conhecimentos, competências e disposições, e que lhes permite intervir profissionalmente no desenvolvimento do seu ensino, do currículo e da escola, como o objetivo de melhorar a qualidade da educação que os alunos recebem. 
Depreende-se que a formação de professores vai além da inicial, é um processo contínuo, permanente. García (1999, p. 136) opta por utilizar o termo "desenvolvimento profissional de professores" ao se referir à formação contínua destes profissionais. Para esse autor, “o conceito 'desenvolvimento' tem uma conotação de evolução e continuidade" (GARCÍA, 1999, p. 137), além de perceber este como algo amplo, que perpassa os modelos singulares/específicos utilizados normalmente para esse fim.

Esse processo, intrínseco à profissão docente, visa, dentre outros objetivos, qualificar o processo de ensino e aprendizagem. Isso nos remete aos diferentes elementos que envolvem a educação, no que diz respeito a professor, aluno, escola como um todo. García (1999, p. 139 , grifo do autor) percebe "o desenvolvimento profissional dos professores como uma encruzilhada de caminhos, como a cola que permite unir práticas educativas, pedagógicas, escolares e de ensino".

Esse autor apresenta modalidades de desenvolvimento profissional docente, baseadas em Sparks e Loucks-Horsley (1990). Uma delas se desenvolve a partir da "reflexão, do apoio mútuo e da supervisão" (GARCÍA, 1999, p. 153). Parte-se do pressuposto que a reflexão permite a retomada, o reconhecimento e análise das ações docentes. Segundo García (1999, p. 153),

0 objetivo de qualquer estratégia que pretenda proporcionar a reflexão consiste em desenvolver nos professores competências metacognitivas que lhes permitam conhecer, analisar, avaliar e questionar a sua própria prática docente, assim como substratos éticos e de valor a ela subjacentes.

Sob essa perspectiva citada por García (1999) acerca das estratégias de instigação da reflexão enquanto meio de formação, destacamos o papel que as atividades de autoavaliação, para as quais a reflexão é central, podem desempenhar na formação docente, no desenvolvimento profissional dos professores e na consecução do trabalho educativo a que se propõem as escolas.
A autoavaliação é aqui entendida como a define Terrasêca (2016, p. 169): “um processo de reflexão colaborativo, formativo e autoformativo [capaz de contribuir] para o desenvolvimento profissional e para a melhoria da escola e do serviço educativo que presta".

Essa autora nos convida a atentar para o sentido que o prefixo "auto" pode assumir no conceito de autoavaliação, apresentando uma definição que assinala a importância da reflexão no processo autoavaliativo, mas o situa para além da esfera pessoal, uma vez que o trabalho educativo (objeto da autoavaliação) é construído de modo intersubjetivo, envolvendo diversos atores sociais (professores e outros profissionais da educação, estudantes e seus familiares):

No conceito de autoavaliação, creio ser imperativo esclarecer o sentido de auto: não porque signifique avaliação de si mesmo ou sobre si mesmo, mas porque consiste em um exercício realizado em conjunto com outros, assente na lógica do confronto intersubjetivo e ajustado no princípio da reflexão sobre o trabalho desenvolvido para melhorar a prestação do serviço educativo. (TERRASÊCA, 2016, p. 167).

Certamente os saberes sobre a autoavaliação e como realizá-la devem ser trabalhados desde o início da formação docente, no contexto de disciplinas, projetos e outras iniciativas acessíveis aos licenciandos. Entretanto, para que se efetive como prática incorporada ao fazer docente, tais aprendizados precisarão ser exercitados continuamente ao longo da trajetória formativa e profissional dos professores, de modo a se tornarem saberes consolidados e integrados de modo orgânico à sua atuação profissional. Até porque a autoavaliação é uma prática complexa e a tarefa de empregá-la como um recurso promotor de melhorias na educação geralmente é marcada por desafios.

Por fim, importa destacar que mesmo sendo a autoavaliação uma prática caracterizada na literatura científica atual (CARAMELO; TERRASÊCA; KRUPPA, 2015; MACBEATH, 2005; TERRASÊCA, 2016) como relevante e até indispensável para a educação, com tal concepção 
reverberando em alguma medida em documentos oficiais divulgados pelo governo brasileiro ${ }^{2}$ e no senso comum, a sua presença na formação docente enquanto objeto de estudo e reflexão, assim como na realidade cotidiana das escolas brasileiras, pode ser descrita como rarefeita e insuficiente.

\section{A reflexão como processo basilar da autoavaliação}

Avançando na discussão sobre a especificidade da autoavaliação enquanto "processo de reflexão colaborativo, ao mesmo tempo formativo e formador" porque fundamentado "na reflexão sobre si e na reflexão com outros sobre os processos para melhorá-los [pessoas e contextos]" (TERRASÊCA, 2016, p. 169), tornase pertinente apresentarmos uma discussão mais aprofundada sobre os conceitos de "reflexão", "reflexividade" e "professor reflexivo", (re)conhecendo suas facetas, especialmente as voltadas a aspectos do campo educacional, e problematizando seus usos e implicações.

Como um primeiro passo nessa direção, cabe retomarmos a conhecida definição apresentada por Libâneo (2002, p. 55) para o conceito de reflexividade:

Reflexividade é uma característica dos seres racionais conscientes; todos os seres humanos são reflexivos, todos pensamos sobre o que fazemos. A reflexividade é uma autoanálise sobre nossas próprias ações, que pode ser feita comigo mesmo ou com outros. Não é inútil recorrer à etimologia: o dicionário Houaiss menciona reflexivo + dade, caráter do que é reflexivo; reflexivo - o que reflete ou reflexiona, que procede com reflexão, que cogita, que se volta sobre si mesmo. 0 termo original latino seria 'reflectere' - recurvar, do-

2 Referências à autoavaliação docente e à reflexão podem ser conferidas, por exemplo, nos Referenciais para o Exame Nacional de Ingresso na Carreira Docente, documento elaborado pelo Ministério da Educação (MEC) e pelo Instituto Nacional de Estudos e Pesquisas Educacionais Anísio Teixeira (Inep). Ao definir as qualidades requeridas de um "bom professor", o documento faz menção à "reflexão sistêmica sobre a própria atuação" (MINISTÉRIO DA EDUCAÇÃO; INSTITUTO NACIONAL DE ESTUDOS E PESQUISAS EDUCACIONAIS ANÍSIO TEIXEIRA, 2010). brar, ver, voltar para trás. Reflexividade parece ser, pois, um termo adequado para designar a capacidade racional de indivíduos e grupos humanos de pensar sobre si próprios.

Esse autor destaca a existência de diferentes concepções de reflexão, apresentando-as de acordo com diferentes autores. Todavia, o que queremos ressaltar ao trazer essa definição é que, ainda que se trate de algo reconhecido como próprio do ser humano, por vezes faz-se necessário estimular, proporcionar, instigar a reflexividade.

Imbricado no conceito de reflexividade trazemos o termo "professor reflexivo". De acordo com Fávero, Tonieto e Roman (2013), o termo professor reflexivo tem origem nos Estados Unidos, surgindo como oposição à formação tecnicista dos professores, tanto em nível inicial como posteriormente, refletindo na prática desses profissionais.

Esse termo tem sido muito utilizado na área educacional na contemporaneidade e possibilitado inúmeros estudos e debates sobre a formação docente nos distintos níveis de escolarização. Alarcão (1996, p. 174), por exemplo, considerada uma das mais reconhecidas estudiosas do assunto, observa que a emergência do paradigma nos processos formativos foi motivada pela necessidade de que o homem pensante pudesse "reencontrar a sua identidade perdida", tivesse condições de questionar "as finalidades da educação" e, com isso,"discutir as metodologias de formação" e tivesse autonomia para "gerir os seus próprios destinos e os do mundo, numa atitude de reconquista da liberdade e emancipação próprias do humano". A esse respeito, Fávero e Tonieto (2010, p. 46, grifo do autor) ressaltam que "é o ato de ser reflexivo que capacita o pensamento a ser 'atribuidor de sentido'".

A ideia de reflexão também foi amplamente tematizada na obra "Como pensamos", pelo filósofo da educação John Dewey (1959). Para ele, há uma nítida distinção entre a reflexão e o ato rotineiro de pensar: enquanto o pensar rotineiro é guiado por impulso, há- 
bito, tradição ou submissão à autoridade, "a reflexão não é simplesmente uma sequência, mas uma consequência - uma ordem de tal modo consecutiva que cada ideia engendra a seguinte num efeito natural e, ao mesmo tempo, apoia-se na antecessora ou a esta se refere" (DEWEY, 1959, p. 14). As ideias de Dewey foram amplamente incorporadas nos escritos de Donald Schön (2000) quando diz que um profissional reflexivo é aquele que consegue ser flexível e inteligente para resolver os problemas cotidianos de sua prática docente, mesmo nas situações de incerteza e imprevisibilidade.

Com o intuito de realizar uma análise crítica das ideias acerca do termo professor reflexivo de Schön, Pimenta (2002) apresenta essa teoria no texto Professor reflexivo: construindo uma crítica, o que nos leva a contemplar cautelosamente as duas perspectivas. Segundo Pimenta (2002, p. 19), Schön (2000) reconhece que a produção de conhecimento se dá a partir da prática profissional, "através da reflexão, análise e problematização desta, e o reconhecimento tácito, presente nas soluções que os profissionais encontram em ato".

Para Schön (2000), esse conhecimento subentendido é pouco diante de novos desafios, 0 que leva o profissional a buscar outros a fim de superar os já interiorizados, seria então "reflexão na ação". Estes conhecimentos no decorrer da prática e diante de novas situações exigem outros, processo que o autor designa como "reflexão sobre a reflexão na ação". Isso tudo "abre perspectivas para a valorização da pesquisa na ação dos profissionais, colocando as bases para o que se convencionou denominar o professor pesquisador de sua prática" (PIMENTA, 2002, p. 20, grifo do autor).

Ao buscarem contextualizar o termo professor reflexivo, Fávero, Tonieto e Roman (2013, p. 282) discorrem acerca dessa proposta: "Cometem graves equívocos e correm sérios riscos de fracassar profissionalmente todos aqueles que confiam cegamente que um processo formativo será capaz de indicar todos os procedimentos técnicos para enfrentar os problemas decorrentes das práticas educativas".

Os princípios propostos por Schön (2000) foram amplamente divulgados e de ampla adesão, visto que sua defesa é a participação direta dos professores nas questões intrínsecas ao processo educativo, valorizando uma formação profissional que evidencie e aproxime pesquisa e prática, ou seja, que as pesquisas provenham do contexto prático do docente, a instituição de ensino em que está inserido, que a prática motive/proporcione novos conhecimentos (PIMENTA, 2002).

Essa preocupação em tornar o professor pesquisador tem legitimidade. Na sociedade contemporânea há uma atitude incoerente quanto ao ensino e à pesquisa. A pesquisa é designada ao pesquisador especialista e o ensino é de responsabilidade do professor. A incoerência se deve ao fato de o pesquisador não experienciar o conhecimento por ele produzido em pesquisa, cabendo ao professor fazer isso na prática diária (GHEDIN, 2002).

$\mathrm{Na}$ tentativa de definir o conceito de reflexão, Zeichner (1993) menciona a supervalorização dos métodos, dos saberes produzidos na universidade, por técnicos, sem sequer haver o olhar de um professor, profissional que executará tal método, atividade e afins. Para esse autor, reflexão também é admitir, identificar que o professor também produz conhecimento (ZEICHNER, 1993).

No livro A formação reflexiva de professores: idéias e práticas, Zeichner (1993) destaca a ascensão do termo reflexão, professor reflexivo, prática reflexiva e outros correlatos, entre as décadas de 1980 e 1990, por vezes utilizados até mesmo de forma incorreta, banal. Zeichner (1993, p. 15) discorre: "Chegou-se mesmo ao ponto de incorporar no discurso sobre prática reflexiva tudo aquilo em que se acredita dentro da comunidade educacional acerca do ensino, aprendizagem, escolaridade e ordem social". Completando esse pensamento, esse mesmo autor alerta: “Assim, só por si, o termo reflexão perdeu vir- 
tualmente qualquer significado" (ZEICHNER, 1993, p. 15).

Nesse contexto, vale ressaltar que Zeichner (1993), tal como Pimenta (2002), faz uma crítica à definição de professor reflexivo defendida por Schön (2000).

Como esclarece Ghedin (2002, p. 132), ainda que Schön (2000) se oponha à racionalidade técnica, proposta que "defende a ideia de que os profissionais solucionem problemas instrumentais mediante a seleção dos meios técnicos", ele parece ter "reduzido a reflexão, como proposta alternativa para a formação, ao espaço da própria técnica".

Acreditar simplesmente que refletir tornará o professor um profissional melhor é arriscado e tende a reduzir essa prática. Para Zeichner (2008, p. 45, grifo nosso), cabe aos formadores de professores, que defendem a formação docente reflexiva, pensarem sobre o fato de que “[...] a 'reflexão' por si mesma significa muito pouco. Todos os professores são reflexivos de alguma forma. É importante considerar o que queremos que os professores reflitam e como".

Refletir é algo próprio do ser humano, é um ato intrínseco aos sujeitos, mas questões como por que refletir, de que forma fazê-lo, quais os objetivos dessa reflexão, são questionamentos que precisam, sim, ser apresentados aos futuros professores, e também, em muitos casos, àqueles já atuantes na área, como salienta Zeichner (2008).

Sob essa perspectiva, e de forma a alertar os formadores de professores acerca do uso do termo reflexão na formação docente, é que Zeichner (2008) questiona se de fato esse conceito resulta efetivamente e positivamente no desenvolvimento desses profissionais ou se trata-se apenas de uma utopia. Para isso, elenca situações que comprometem a sua efetivação:

1) o foco sobre a ajuda aos professores para melhor reproduzirem práticas sugeridas por pesquisas conduzidas por outras e uma negação da preparação dos docentes para exercitarem seus julgamentos em relação ao uso dessas práticas; 2) um pensamento de 'meio e fim', o qual limita a essência das reflexões dos professores para questões técnicas de métodos de ensino e ignora análises dos propósitos para os quais eles são direcionados; 3) uma ênfase sobre as reflexões dos professores sobre o seu próprio ensino, desconsiderando o contexto social e institucional no qual essa atividade acontece; e 4) uma ênfase sobre como ajudar os professores a refletirem individualmente. (ZEICHNER, 2008, p. 544).

É imprescindível que se tenha esclarecimento acerca dessas questões, a fim de não reproduzir concepções ou práticas equivocadas e contrárias aos princípios de sua fundamentação, no caso da reflexão e também da autoavaliação.

Zeichner (2008) sinaliza o quanto a valorização da reflexão docente pode estar ligada à submissão, ao controle, ao cumprimento, mesmo que de forma discreta, de servir a um sistema maior. Segundo esse autor, "os professores devem agir com clareza política maior sobre quais interesses estão sendo privilegiados por meio de suas ações cotidianas" (ZEICHNER, 2008, p. 546).

Ao abordarmos, na presente pesquisa, o termo reflexão, professor reflexivo, prática reflexiva, estamos imbuídos da compreensão de que a autoavaliação, que pode ser praticada pelos profissionais da educação, está assentada essencialmente num processo de reflexão, dando-se a partir de uma prática reflexiva, a partir de objetivos preestabelecidos, num movimento de formação contínua e constante desses profissionais. Contudo, como alerta Terrasêca (2016, p. 170), para tornar isso realidade é preciso transformar a cultura de avaliação hoje reinante na escola e em outros espaços de formação, implica compreender a avaliação como "um processo simultaneamente formativo e formador".

Zeichner (2008, p. 545) também é enfático quanto à formação docente reflexiva:

A formação docente reflexiva, que realmente fomenta o desenvolvimento profissional, deveria somente ser apoiada, em minha opinião, se ela estiver conectada a lutas mais amplas por 
justiça social e contribuir para a diminuição das lacunas na qualidade da educação disponível para estudantes de diferentes perfis, em todos os países do mundo.

Concordamos com a posição defendida por Zeichner (2008), pois acreditamos que é fundamental aos que exercem a docência, indiferente do nível atendido, a visualização e consideração das dimensões sociais e políticas dos processos reflexivos e autoavaliativos.

Nessa direção, Pimenta (2002) salienta a significância do ensino como prática reflexiva, em que a prática docente é geradora da produção de conhecimento, e, analogamente ao movimento feito por Zeichner (2008), levanta alguns questionamentos: "Que tipo de reflexão tem sido realizada pelos professores? As reflexões incorporam um processo de consciência das implicações sociais, econômicas e políticas da atividade de ensinar? Que condições têm os professores para refletir?" (PIMENTA, 2002, p. 22).

Diante disso é que Pimenta questiona a teoria defendida por Schön (2000), de destaque à prática do professor, o que a torna arriscada, podendo afetar negativamente o uso da reflexão. Termos como "praticismo, individualismo, hegemonia autoritária e modismo" são citados por Pimenta (2002, p. 22) como consequências dessa prática nos moldes defendidos por Schön (2000). Os elementos apresentados são caracterizados por conceberem a reflexão como algo autossuficiente/independente (PIMENTA, 2002).

Utilizando-se de diferentes autores, Pimenta (2002) indica que possivelmente Schön (2000) sabia das limitações de sua teoria, e que isso provavelmente se devia ao fato de este autor ter enfocado as práticas individuais e não de um movimento maior, que previsse mudança institucional e social. Para essa autora, o que acaba ocorrendo a partir da prática reflexiva, na concepção de Schön (2000), é um reducionismo técnico das práticas docentes (PIMENTA, 2002). Ademais, Pimenta (2002, p. 24) aponta que:
O saber docente não é formado apenas da prática, sendo também nutrido pelas teorias da educação. Dessa forma, a teoria tem importância fundamental na formação dos docentes, pois dota os sujeitos de variados pontos de vista para uma ação contextualizada, oferecendo perspectivas de análise para que os professores compreendam os contextos históricos, sociais, culturais, organizacionais e de si próprios como profissionais.

Os autores críticos de Schön salientam, nesse sentido, que não pode haver uma restrição à sala de aula como foco de investigação da prática docente.

Investigar, produzir saberes a partir da própria experiência é significativo e altamente desejável. 0 professor torna-se pesquisador de sua ação/prática, diante de situações inesperadas, a partir de decisões repentinas, optando seguir por um caminho e não por outro, ou tomando uma atitude em vez de outra. 0 professor se constrói professor diariamente, no decorrer de sua atuação, da própria experiência, é um aprendiz constante. Entretanto, não só em razão da prática, pois a teoria é essencial na educação e na função social que cabe ao professor.

São amplas as discussões acerca da relação teoria e prática, e interpretações diversas acerca da valorização de cada uma, o que nos leva a defender a importância de tomá-las como articuladas, imbricadas mesmo, no contexto educacional. Isso, entretanto, não tem sido abordado como deveria nos currículos de formação de professores, como avalia Pimenta (2002, p. 20):

Encontramos em Schön uma forte valorização da prática na formação dos profissionais; mas uma prática refletida, que lhes possibilite responder às situações novas, nas situações de incerteza e indefinição. Portanto, os currículos de formação de profissionais deveriam propiciar o desenvolvimento da capacidade de refletir. Para isso, tomar a prática existente (de outros profissionais e dos próprios professores) é um bom caminho a ser percorrido desde o início da formação, e não apenas ao final, como tem ocorrido com o estágio. 
Esse é um elemento de extrema validade nas ideias de Schön (2000): pesquisar a própria prática, refletir a partir da prática, produzir conhecimento a partir da própria experiência. No entanto, conforme indica Pimenta (2002), é preciso ter cuidado com as dimensões dessa "prática refletida", para que não haja um reducionismo de teoria/conhecimento e uma supervalorização do instrumental, da técnica, da prática por si só.

Como apresentamos no decorrer do texto, refletir sobre aspectos pontuais em sala de aula é extremamente importante, assim como considerar aspectos mais amplos, aspectos da sociedade como um todo, pois consideramos que o professor é um agente político.

Nesse contexto, Zeichner (2008) cita o quanto a reflexão docente está ligada à questão da "justiça social" na busca por uma sociedade melhor, sem que necessariamente o professor precise ministrar aulas enfocando questões políticas do ensino. 0 que o professor precisa é ter conhecimento suficiente para ministrar aulas que propiciem a construção de aprendizados por parte dos estudantes e lhes deem condições de pleno exercício de sua cidadania, buscando relacionar esse conhecimento teórico com a realidade de cada estudante, aproximando-o do contexto escolar. Segundo esse autor, o professor precisa ter consciência de suas ações e dos possíveis efeitos delas sobre os aprendizes, para que tais ações "não limitem as chances de vida de seus alunos; que eles tomem decisões com uma consciência maior das possíveis consequências políticas que as diferentes escolhas podem ter" (ZEICHNER, 2008, p. 546).

Em vista disso, retomamos a preocupação em equacionar prática e teoria trazendo as considerações de Pimenta (2002, p. 26), quando afirma que "0 papel da teoria é oferecer aos professores perspectivas de análise para compreenderem os contextos históricos, sociais, culturais, organizacionais e de si mesmos como profissionais, nos quais se dá sua atividade docente, para neles intervir, transformando-os."
O professor vivencia constantemente situações desafiadoras e dilemas que exigem desse profissional respostas imediatas, resultados de sua bagagem de conhecimento teórico e de experiência. Para saber lidar com os desafios diários, o professor precisa estar disposto a repensar e reorganizar a sua prática constantemente, como aponta Ghedin (2002, p. 135, grifo do autor):

A experiência docente é espaço gerador e produtor de conhecimento, mas isso não é possível sem uma sistematização que passa por uma postura crítica do educador sobre as próprias experiências. Refletir sobre os conteúdos trabalhados, as maneiras como se trabalha, a postura frente aos educandos, frente ao sistema social, político, econômico, cultural é fundamental para se chegar à produção de um saber fundado na experiência. Deste modo, o conhecimento que o educador 'transmite' aos educandos não é somente aquele produzido por especialistas deste ou daquele campo específico de conhecimento, mas ele próprio se torna um especialista do fazer (teórico-prático-teórico).

A reflexão acerca da prática docente tem sido reconhecida como importante, uma reflexão que considera indissociável a teoria e a prática, mas, e acima de tudo, devemos salientar que esta seja uma reflexão crítica, que possibilite questionamento, a desacomodação, que tenha propósitos educacionais e sociais. É extremamente importante atentar para o significado dessa reflexão.

De acordo com Ghedin (2002, p. 138), "Refletir criticamente significa colocar-se no contexto de uma ação, na história da situação, participar em uma atividade social e tomar postura ante os problemas". Uma postura crítica reflexiva servirá, além da qualificação do docente e do ensino por ele ofertado, como um guia a orientar o olhar dos sujeitos por ele educados. 0 professor precisa educar para a superação.

Nesse sentido, entendemos que as atividades relacionadas à prática da reflexão e da autoavaliação têm muito a contribuir para a área da educação. E quanto mais condições 
forem dadas aos profissionais da área para poderem envolver-se com essas atividades conhecendo suas potencialidades, mas também os limites e reducionismos associados a certas apropriações delas feitas, mais aportes estarão à sua disposição para, de forma sistematizada e consciente, desempenharem seu papel profissional plenamente, ou seja, sem perder de vista as dimensões teórica, técnica, ética e política do trabalho educativo.

0 caráter social da ação do professor exige de tal profissional essa postura de reflexão crítica, visualizando novas formas de fazer educação, estimulando a autonomia e a reflexividade nos estudantes a fim de auxiliar na emancipação dos jovens cidadãos, para que estes se posicionem criticamente e possam vir a transformar a situação de exploração a que são submetidos nessa sociedade capitalista em que vivemos (GHEDIN, 2002).

Explanada a sua complexidade, compreendemos os múltiplos dilemas que afetam e desafiam a prática docente. Dessa maneira, a autoavaliação, realizada de forma sistemática, revela-se um excelente mecanismo de apropriação de saberes na busca por qualificação, de conhecimento sobre si e, como consequência, sobre a sociedade em seus diferentes âmbitos sociais.

\section{A educação superior diante da fragilidade da profissionalização docente e do desafio da autoavaliação: a formação inicial e continuada como espaço de construção de saberes}

Os obstáculos encontrados na profissão docente na contemporaneidade são muitos e de diferentes ordens. As transformações ocorridas na sociedade impulsionam e exigem desse profissional "multisaberes", e não apenas os saberes próprios de sua área de formação.
A profissionalização docente é considerada vulnerável, frágil, inconstante, instável, e isso se deve a inúmeros fatores que, no decorrer da história, a levaram a essa condição, o que resultou também no desprestígio, um aspecto de inferiorização da profissão docente.

Tardif (2000, p. 6) indica que "o que distingue as profissões das outras ocupações é, em grande parte, a natureza dos conhecimentos que estão em jogo". 0 que se busca na formação de professores, no ensino, é confirmar a profissão docente como tal, num movimento de profissionalização.

Nesse contexto, Tardif (2000) cita os principais aspectos do conhecimento profissional, e dentre eles são apresentados: a aquisição de conhecimentos científicos, desenvolvidos a partir de uma longa formação efetivada normalmente em universidades; o conhecimento a partir de problemas práticos, concretos; a utilização e o domínio de conhecimentos científicos da área; a possibilidade de realizar "uma autogestão dos conhecimentos pelo grupo dos pares, bem como um autocontrole da prática" (TARDIF, 2000, p. 7).

Além desses aspectos, o que nos chamou atenção é o destaque que ele dá ao trazer que o conhecimento profissional não se baseia apenas em conhecimentos técnicos, mas que:

[...] exigem sempre uma parcela de improvisação e de adaptação a situações novas e únicas que exigem do profissional reflexão e discernimento para que possa não só compreender o problema como também organizar e esclarecer os objetivos almejados e os meios a serem usados para atingi-los. (TARDIF, 2000, p. 7).

Outro aspecto citado é a formação continuada. Tardif (2000, p. 7) disserta: "os profissionais devem, assim, autoformar-se e reciclar-se através de diferentes meios, após seus estudos universitários iniciais." Estas são algumas das características do conhecimento profissional, segundo Tardif (2000). No decorrer desse trabalho, esses elementos foram citados como aspectos inerentes à profissão docente, indo ao encontro do que traz Tardif (2000). 
Para esse autor, o que tem se objetivado com o movimento de profissionalização do ofício do professor é "conseguir desenvolver e implantar essas características dentro do ensino e na formação de professores" (TARDIF, 2000, p. 7). E aponta que se de fato isso acontecer, "o ensino deixará então de ser um ofício para tornar-se uma verdadeira profissão" (TARDIF, 2000, p. 8).

Ao referir-se à educação, Tardif (2000, p. 8) define a profissionalização como "uma tentativa de reformular e renovar os fundamentos epistemológicos do ofício de professor e de educador, assim como da formação para o magistério".

A partir dos elementos apresentados, fica evidenciado o quanto a autoavaliação, enquanto instrumento de reflexão da própria prática, é imprescindível no movimento de profissionalização.

Diante desse cenário, Fávero, Castelli e Marques (2015) destacam a realidade dos professores universitários, cuja consideração pode ser valiosa à análise aqui empreendida não apenas por apresentar pontos de aproximação com a realidade vivenciada por docentes atuantes em outros níveis de ensino, permitindo-nos construir reflexões sobre a profissão docente de maneira geral, mas porque oferece pistas para problematizarmos também o papel da educação superior no trabalho com as temáticas da avaliação e da autoavaliação. E aqui precisamos considerar mais amplamente esse papel, uma vez que ele impacta a sociedade não apenas em razão da forma como as instituições de ensino superior conduzem seus processos avaliativos nos cursos que capacitam profissionais de diferentes áreas, ou por causa do modo como se dá o ensino desses temas aos futuros docentes nos cursos de formação de professores, mas também pelo fato de que a universidade tem o poder de catalisar mudanças na educação, especialmente quando suas ações constituem a vanguarda do processo de criação de novas ideias, conceitos, métodos etc.

Segundo Fávero, Castelli e Marques (2015), as mudanças ocorridas na sociedade atual estão causando, nos professores, uma crise de identidade profissional, uma busca por um novo conceito de profissionalização da docência. E, para que a profissionalização da docência ocorra, muitos são os desafios que precisam ser enfrentados. Um exemplo disso é conseguir estabelecer relações entre os conteúdos formais e os aspectos que envolvem o complexo cenário educativo. A autoavaliação é por eles considerada uma prática potencialmente eficaz nesse processo. "Autoavaliar a profissionalização docente", ressaltam Fávero, Castelli e Marques (2015, p. 182, grifo do autor), "significa dar-se conta de que a docência não é uma ação espontânea ou naturalizada que 'se aprende fazendo'”, de que a experiência ensina a dar aula e de que para ser professor basta dominar o conteúdo e manejar um conjunto de 'técnicas didáticas'”. Para ser docente são necessários "múltiplos saberes que podem ser aperfeiçoados por meio de formação continuada". A autoavaliação possibilita que o professor perceba a importância da prática participativa que torna a aula universitária mais dinâmica e comprometida.

Tomando por referência as reflexões de Dias Sobrinho (2000), que ressalta a distinção entre medir e avaliar, Fávero, Castelli e Marques (2015, p. 182) também ressaltam o papel da autoavaliação nos processos avaliativos, os quais implicam em "mobilizar um conjunto de reflexões que possibilitam perceber a avaliação como um processo formativo e não como um restrito instrumento de certificação e medida". Com isso é possível compreender que a avaliação na educação superior não seria mais reduzida à aplicação de uma prova que reforça a visão mecanicista e simplificadora, "constituída por uma simples tecnificação da formação” (FÁVERO; CASTELLI; MARQUES, 2015, p. 182).

Nesse aspecto, é possível afirmar, com Fávero, Castelli e Marques (2015, p. 183), que a autoavaliação pode se constituir um "processo reflexivo capaz de gestar uma avaliação autêntica", pois é capaz de melhorar o processo 
de ensino e de aprendizagem que ocorre na interação de um professor com seus alunos.

Condemarín e Medina (2005) indicam dez aspectos que caracterizam uma avaliação autêntica: 1) constitui uma instância destinada a melhorar a qualidade das aprendizagens; 2) constitui um processo participativo; 3) diferencia avaliação de qualificação; 4) é coerente com os paradigmas da reforma educacional; 5) é coerente com as atuais compreensões sobre a aprendizagem da linguagem oral e escrita; 6) centra-se nos pontos fortes dos alunos; 7) constitui um processo multidimensional; 8) considera os benefícios pedagógicos envolvidos na análise dos erros; 9) favorece a equidade educativa; e 10) favorece o desenvolvimento profissional dos professores. Todas estas características e princípios, na avaliação de Fávero, Castelli e Marques (2015, p. 183),

[...] potencializam a ideia de que a mudança, não só dos procedimentos avaliativos, mas principalmente da concepção de avaliação que perpassa as ações dos docentes universitários, acaba produzindo uma nova forma de compreender a dinâmica do conhecimento, a relação pedagógica entre professor e alunos e, principalmente a formação de futuros profissionais.

Os resultados efetivos de uma avaliação autêntica, concretizados por um processo de autoavaliação, são ressaltados por Condemarín e Medina (2005, p. 26) quando dizem que tais práticas "[...] fortalecerão a autoestima e o profissionalismo dos professores, porque eles terão outras instâncias para mostrar sua criatividade e autonomia para propor situações educativas nas quais interajam com seus alunos como mediadores eficientes". Da mesma forma, para os estudantes, os resultados da avaliação autêntica "também fortalecerão sua capacidade de tomar decisões, visto que contarão com uma pluralidade de meios para avaliá-las diante dos próprios alunos, de suas famílias e de outros atores do sistema" (CONDEMARÍN; MEDINA, 2005, p. 26).

A ideia de autoavaliação e de avaliação autêntica está também em sintonia com a intencionalidade do Sistema Nacional de Ava- liação Superior (Sinaes), criado em 2004 e que tem possibilitado a ampliação de uma nova concepção no que diz respeito à qualidade da educação superior. Conforme ressaltam Fávero e Pagliarin (2018, p. 37), a criação do Sinaes e sua implementação na forma de avaliar os processos formativos dos egressos fez com que "a qualidade estaria mais próxima dos saberes construídos pelos alunos do que com o rendimento do aluno em si, ou seja, pensa-se a avaliação a partir de um perfil profissional que se deseja, e não apenas a verificação de conteúdos aprendidos". Nessa mesma direção, Garcia (2009, p. 206) argumenta que a avaliação implica diretamente nas atitudes dos estudantes face ao estudo, pois possibilita a construção de experiências formativas sob diversos aspectos, podendo "influenciar o modo como os estudantes planejam e utilizam o tempo dos estudos, atribuem prioridade e significado as diversas tarefas acadêmicas, e, de modo amplo, como eles se desenvolvem academicamente". Por isso, para Fávero e Pagliarin (2018, p. 38), "é preciso que os professores da educação superior repensem os formatos avaliativos, os instrumentos, bem como o objetivo das avaliações da aprendizagem dos alunos desse nível de ensino". Contudo, para tanto, são necessários: uma "mudança de concepção sobre avaliação", "rever as formas de avaliação" e, principalmente, "favorecer a qualidade de aprendizagem dos alunos".

\section{Autoavaliação na formação docente sob a perspectiva dos profissionais da educação}

Nesta seção são apresentados os resultados da pesquisa empírica realizada com profissionais da educação visando investigar se e como o tema da autoavaliação foi abordado nos processos de formação inicial e/ou continuada aos quais tiveram acesso. A pesquisa foi realizada no ano de 2019, com um grupo de dez profissionais, sendo cinco deles professores e cinco 
coordenadores pedagógicos, todos atuantes em escolas de educação básica da rede pública e privada de ensino do noroeste do estado do Rio Grande do Sul.

Ao investigar, via questionário, se existiu e como se deu o contato com o tema autoavaliação na formação inicial e/ou continuada desses profissionais, as respostas obtidas foram semelhantes, evidenciando que as ações voltadas à abordagem do assunto, nesse contexto, foram escassas. Os participantes da pesquisa relataram um contato pontual e superficial, que remetia indiretamente à autoavaliação como forma de avaliação, mas nada deliberadamente voltado à discussão da questão. A maioria teve contato com o tema em debates, de forma dialogada em grupos, algo sem muito aprofundamento. Nenhum dos participantes reportou a existência de conteúdos relacionados à autoavaliação integrando o currículo de seu curso de graduação, ou seja, como tópico específico de alguma disciplina ofertada na grade curricular. Nem mesmo na formação continuada eles tiveram alguma oportunidade de estudar e/ou discutir sobre processos autoavaliativos de forma mais aprofundada, sendo a importância destes destacada nas observações sobre avaliação, mas sem o acesso a saberes que, conforme declararam os profissionais, pudessem embasar a efetivação futura de práticas nesse sentido.

A alusão à reflexão como germe ou condição basilar da autoavaliação esteve presente nas tentativas de quase todos os participantes de definirem o que entendem por autoavaliação. Entretanto, tanto a reflexão quanto a autoavaliação são concebidos, pela maioria, como processos cuja concretização no contexto escolar dependeria mais da iniciativa individual de cada professor do que de possíveis movimentos de articulação coletiva ou incentivos/ proposições institucionais.

0 conjunto desses achados nos permite afirmar que, para os sujeitos participantes de nossa pesquisa, a formação (inicial e continuada) a que tiveram acesso não lhes oportunizou o estudo do tema autoavaliação, nem os colocou em contato com situações de aprendizagem que lhes inspirasse a significar a autoavaliação como um recurso que devesse ser incorporado às suas práticas profissionais cotidianas. Nesse sentido, nosso estudo corrobora achados de outros pesquisadores (CARVALHO, 2011; FÁVERO; CASTELLI; MARQUES, 2015; SILVA; ZANIN, 2017) que já haviam alertado para o fato de que, mesmo sendo reconhecida como uma ferramenta útil pelos profissionais da educação que têm emitido suas opiniões sobre o assunto nas pesquisas, a prática da autoavaliação ainda é um elemento ausente da realidade de parcela significativa das escolas brasileiras, em parte porque é também ausente da realidade dos espaços de formação.

Os cursos de graduação nos quais se diplomaram os participantes de nossa pesquisa são variados (Pedagogia, Educação Física, Filosofia, História, Artes), mas o teor dos comentários por eles tecidos sobre o tema foi muito similar. E pelo que consta na literatura científica atual que pudemos revisar, é possível afirmar que as falhas da formação oferecida pelas universidades aos futuros professores incidem não apenas sobre a questão da autoavaliação, mas abrangem a temática da avaliação de modo geral.

Villas Boas e Soares (2016) encontraram resultados parecidos em pesquisa realizada sobre avaliação em cursos de licenciatura. Apesar de não enfocarem especificamente a questão da autoavaliação, as descobertas e conclusões a que chegaram sobre a temática da avaliação muito se aproximam de nossos achados. Na análise que apresentam, chegam à conclusão de que esses temas, além de não serem abordados de modo articulado com $o$ ensino e a aprendizagem nas universidades, não têm sido incorporados ao currículo dos cursos de licenciatura como deveriam, fazendo com que, na prática, não recebam a devida atenção (VILLAS BOAS; SOARES, 2016). Assim, podemos afirmar, a partir das pesquisas acima referidas e também do nosso estudo, que o lugar conferido à avaliação, e, consequente- 
mente, à autoavaliação, nos cursos de formação docente, tem se mostrado, na atualidade, ainda periférico.

Considerando o que afirmam Rombaldi e Canfield (1999, p. 33) sobre o fato de que "a formação profissional envolve algo mais do que a estrutura curricular", pois depende da "relação estabelecida entre a fundamentação teórica e os procedimentos a serem adotados" para a construção da profissionalidade docente pelos futuros professores, fica evidenciada a necessidade de estudos que explorem essas diferentes facetas da formação real à qual estão tendo acesso os licenciandos. Vale a pena investigar, nesse sentido, se as formas de avaliação a que têm sido expostos enquanto estudantes os confronta com a oportunidade de explorar possibilidades inovadoras nesse campo, se os estágios curriculares estão colocando-os em contato com dúvidas e inquietações relacionadas aos processos avaliativos e se os processos de reflexão e autoavaliação têm sido tomados como recursos formativos e formadores.

Os professores participantes da pesquisa foram questionados acerca das formações continuadas, se atualmente a autoavaliação vem sendo abordada com maior destaque ou não nessas ocasiões. Novamente as respostas se assemelham: pouco tem-se avançado. Ainda que temáticas como avaliação formativa e prática docente reflexiva por vezes figurarem na pauta das propostas de formação continuada que chegam às escolas, são tímidas as iniciativas no sentido de avançar na discussão do tema.

Essa situação leva a um círculo vicioso, pois no momento em que o professor, ao longo de sua formação, não tem nenhuma aproximação sistemática e aprofundada com essas temáticas, não saberá como efetivar processos de avaliação-autoavaliação-reflexão quando professor, e, consequentemente, não terá aporte teórico para ensinar seus alunos, e assim seguirá o círculo. Devemos indagar, nesse sentido, sobre quais seriam os caminhos por meio dos quais poderíamos chegar à ruptura desse círculo. Em que medida eles estão atrelados a processos que implicam a reestruturação da educação superior e da formação oferecida atualmente pelas universidades? Nessa direção, cabe também questionarmos quais mudanças são requeridas das escolas de educação básica e do contexto social mais amplo onde se inserem.

Em nossa pesquisa, questionários foram direcionados a coordenadores pedagógicos inseridos nas mesmas escolas onde trabalham os professores que participaram da pesquisa. Procuramos saber qual a relação desses profissionais e das instituições onde atuam com a efetivação/motivação da autoavaliação no contexto escolar. 0 que foi possível observar, a partir das respostas obtidas, é que pouco se tem realizado para promover a introdução dessa temática, seja enquanto objeto de estudo, seja enquanto prática incorporada ao agir docente, nos contextos escolares dos quais participam os sujeitos em questão. Parece faltar conhecimento e familiaridade em relação às possibilidades de uso desse recurso, realidade esta alimentada por uma visão mais estreita dos processos avaliativos e sua função educativa.

Isso fica ilustrado na resposta de um dos coordenadores acerca da possibilidade da autoavaliação nas escolas:

Acredito que sim, nas escolas no modo geral, pois onde trabalho, não sei se seria possível de forma que gerasse muitos atritos, pois a resistência com certeza será grande. A visão de autoavaliação ainda é muito reducionista a buscar defeitos, e isso de ver o que se está sendo feito 'errado' é muito complicado em nosso meio, os professores não gostam de receber críticas/sugestões, mesmo que seja para ajudar a melhorar suas práticas. Alguns, devido a seu tempo de atuação, chegam a responder: 'Eu tenho 22 anos de experiência, sempre fiz assim. E agora querem vir me ensinar como fazer! Façame um favor!' (COORDENADOR PEDAGÓGICO, ESCOLA A).

O discurso desse profissional, que poderia assumir, na escola, a função de orientar os professores na efetivação de processos avaliativos com cunho formativo, dá ênfase aos empecilhos que se colocam à tarefa de produzir autoava- 
liações, da resistência oferecida pelos pares a essa opção. 0 erro (ou "a busca por defeitos") também figura, em seus apontamentos, como algo associado, pelos professores com os quais convive, à avaliação, assim como o temor de serem criticados e cobrados a operar mudanças em seus modos de serem professores. A referência feita por este coordenador pedagógico à fala de uma professora que trabalha em sua escola ("Eu tenho 22 anos de experiência, sempre fiz assim. E agora querem vir me ensinar como fazer! Faça-me um favor!") é explicada por ele como um exemplo do fato de que, na visão de muitos professores, quem deve ser submetido a processos avaliativos é o estudante, e não o professor, ainda menos o que tem ampla experiência profissional, visto que já teria uma trajetória de conhecimento acumulado suficiente para realizar o trabalho educativo que lhe cabe, não precisando "ser ensinado" nesse nível.

\section{Considerações finais}

A autoavaliação é um processo que permite aos profissionais da educação, com base na reflexão sobre os processos educativos que se dão nos diferentes âmbitos educacionais, analisar a sua própria prática, a relação desta com as ações de outros sujeitos com os quais interagem e o contexto onde estas se dão, buscando maior conhecimento e qualidade da educação. Assim como outros pesquisadores (DAY, 1993; TERRASÊCA, 2016; VILLAS BOAS; SOARES, 2016), entendemos que a avaliação e a autoavaliação são temas complexos, sendo necessário atentar para o aspecto humano da questão, pois avaliar envolve mudanças e reconfiguração de atitudes, muitas das quais estão fortemente arraigadas nos sujeitos, chegando a compor suas identidades pessoais e profissionais. Nesse sentido, o ensino da avaliação/autoavaliação precisa ser repensado na educação superior, uma vez que a abordagem desses temas não tem sido satisfatória nos cursos de formação de professores, o que requer uma atenção cuidadosa com os fatores que fazem com que exista e persista essa insuficiência na formação oferecida pelas universidades. Assim como mostra-se de extrema importância o estudo e discussão do tema para além da formação inicial, ou seja, nas oportunidades de formação continuada e no cotidiano escolar, a partir da iniciativa dos próprios professores atuantes nas escolas de educação básica, das equipes diretivas dessas instituições ou daqueles que, mesmo não compondo a comunidade escolar, venham a propor a incorporação desses temas na pauta de debates que contemplem melhorias na educação.

Com base na análise aqui empreendida, podemos afirmar que é imprescindível construirmos esse conhecimento acerca do tema para não incorrermos em reducionismos ou no investimento em práticas incongruentes com os princípios que perseguimos enquanto profissionais da educação.

Ratificamos a compreensão da autoavaliação como prática sistemática da reflexão. Todavia, como alertam diversos autores lembrados ao longo deste artigo, é preciso saber o que e como refletir, ter em mente os objetivos dessa ação, devendo, os que se propõem a isso, realizá-la de forma cuidadosa e consciente de sua dimensão ético-política. Além disso, aspectos extraescolares devem ser considerados, dimensionando as inúmeras questões que afetam a vida escolar dos estudantes.

O desenvolvimento profissional é apenas umas das contribuições da autoavaliação e da reflexão sobre a própria prática. A partir do que foi apresentado até o momento, estamos convictos de que as contribuições dessa prática no campo da educação são inúmeras, tendo em vista a busca constante por uma educação de qualidade e, acima de tudo, por uma sociedade mais democrática e justa.

\section{REFERÊNCIAS}

ALARCÃO, Isabel. Ser professor reflexivo. In: ALARCÃO, Isabel (org.). Formação reflexiva de 
professores: estratégias de supervisão. Porto: Porto Editora, 1996. p. 171-189.

BARDIN, Laurence. Análise de conteúdo. Portugal: Edições 70, 2010.

CARAMELO, João; TERRASÊCA, Manuela; KRUPPA, Sônia Maria Portella. A autoavaliação pode fazer diferença na qualidade da educação: conversando com John MacBeath. Educação e Pesquisa, n. 41, p. 1601-1615, dez. 2015. Disponível em: https:// dx.doi.org/10.1590/S1517-970220154100002. Acesso em: jan. 2019.

CARVALHO, Esmeralda Maria Rodrigues de. Autoavaliação e desenvolvimento profissional docente: estudo exploratório. 2011. 183f. Dissertação (Mestrado em Ciências da Educação) - Instituto de Educação, Universidade do Minho, Braga, 2011.

CONDEMARÍN, Mabel; MEDINA, Alejandra. Avaliação autêntica: um meio para melhorar competências em linguagem e comunicação. Porto Alegre: Artmed, 2005.

DAY, Christopher. Avaliação do desenvolvimento profissional dos professores. In: NÓVOA, António (org.). Avaliações em educação: novas perspectivas. Porto, PT: Porto Editora, 1993. p. 102-108.

DEWEY, John. Como pensamos. 3. ed. São Paulo: Companhia Editora Nacional, 1959.

DIAS SOBRINHO, José. Avaliação da educação superior. Petrópolis, RJ: Vozes, 2000.

FÁVERO, Altair Alberto; CASTELLI, Maria Dinorá Baccin; MARQUES, Marta. Autoavaliação e o desenvolvimento profissional do docente universitário. In: FÁVERO, Altair Alberto; TONIETO, Carina; ODY, Leandro Carlos (org.). Docência universitária: pressupostos teóricos e perspectivas didáticas. Campinas, SP: Mercado de Letras, 2015. p. 171-186.

FÁVERO, Altair Alberto; PAGLIARIN, Lidiane Limana Puiati. A avaliação da aprendizagem na educação superior: princípios e fundamentos. In: TAUCHEN, Gionara; FÁVERO, Altair Alberto (org.). Avaliação do ensino superior: perspectivas de ensino e de aprendizagem. vol. 4. Curitiba: CRV, 2018. p. 35-47.

FÁVERO, Altair Alberto; TONIETO, Carina. Educar o educador: reflexões sobre a formação docente. Campinas, SP: Mercado de Letras, 2010.

FÁVERO, Altair Alberto; TONIETO, Carina; ROMAN, Marisa Fátima. A formação de professores reflexivos: a docência como objeto de investigação. Educação,
Santa Maria, RS, v. 38, n. 2, p. 277-288, 2013.

GARCIA, Joe. Avaliação e aprendizagem na educação Superior. Estudos em Avaliação Educacional, São Paulo, v. 20, n. 43, p. 201-213, maio/ago. 2009.

GARCÍA, Carlos Marcelo. Formação de professores: para uma mudança educativa. Porto, PT: Porto Editora, 1999.

GHEDIN, Evandro. Professor reflexivo: da alienação da técnica à autonomia da crítica. In: PIMENTA, Selma G.; GHEDIN, Evandro (org.). Professor reflexivo no Brasil: gênese e crítica de um conceito. 2. ed. São Paulo: Cortez, 2002. p. 129-150.

GIL, Antonio Carlos. Métodos e técnicas de pesquisa social. 6. ed. São Paulo: Atlas, 2008.

LIBÂNEO, José Carlos. Reflexividade e formação de professores: outra oscilação do pensamento pedagógico brasileiro? In: PIMENTA, Selma G.; GHEDIN, Evandro (org.). Professor reflexivo no Brasil: gênese e crítica de um conceito. 2. ed. São Paulo: Cortez, 2002. p. 63-93.

LIMA, Telma Cristiane Sasso de; MIOTO, Regina Célia Tamaso. Procedimentos metodológicos na construção do conhecimento científico: a pesquisa bibliográfica. Revista Katálysis, Florianópolis, v. 10, p. 37-45, 2007.

MACBEATH, John. et al. A história de Serena: viajando rumo a uma escola melhor. Porto: ASA, 2005.

MINISTÉRIO DA EDUCAÇÃO (MEC); INSTITUTO NACIONAL DE ESTUDOS E PESQUISAS EDUCACIONAIS ANÍSIO TEIXEIRA (INEP). Referenciais para o exame nacional de ingresso na carreira docente: documento para consulta pública. Brasília, DF, 2010.

PIMENTA, Selma G. Professor reflexivo: construindo uma crítica. In: PIMENTA, Selma G.; GHEDIN, Evandro (org.). Professor reflexivo no Brasil: gênese e crítica de um conceito. 2. ed. São Paulo: Cortez, 2002.

ROMBALDI, Rosiane de Magalhães; CANFIELD, Marta de Salles. A formação profissional em educação física e o ensino da avaliação. Kinesis, Santa Maria, RS, n. 21, p. 31-36, 1999.

SCHÖN, Donald. Educando o profissional reflexivo: um novo design para o ensino e a aprendizagem. Porto Alegre: Artmed, 2000.

SILVA, Ivone Maria Mendes; ZANIN, Nauíra Zanardo. Espaços e tempos vividos na escola: implicações para os processos de subjetivação e 
ensino-aprendizagem na perspectiva de jovens estudantes e seus professores. Gavagai - Revista Interdisciplinar de Humanidades, v. 4, n. 2, p. 121-143, dez. 2017.

SPARKS, Dennis; LOUCKS-HORSLEY, Susan. Models of staff development. In: HOUSTON, W. R. (ed.). Handbook of research on teacher education. New York: Mcmillan, 1990. p. 234-251.

TARDIF, Maurice. Saberes profissionais dos professores e conhecimentos universitários: elementos para uma epistemologia da prática profissional dos professores e suas conseqüências em relação à formação para o magistério. Revista Brasileira de Educação, n. 13, p. 5-24, jan./abr. 2000.

TERRASÊCA, Manuela. Autoavaliação, avaliação externa... Afinal para que serve a avaliação das escolas? Cadernos CEDES, Campinas, SP, v. 36, n. 99, p. 155-174, ago. 2016. Disponível em: http://www.scielo.br/scielo.php?script $=$ sci arttext\&pid=S0101-32622016000200155\&lng=p t\&nrm=iso. Acesso em: 09 maio 2019.
VEIGA, Ilma Passos Alencastro. Docência como atividade profissional. In: VEIGA, Ilma Passos Alencastro; D’ÁVILA, Cristina Maria (org.). Profissão docente: novos sentidos, novas perspectivas. Campinas, SP: Papirus, 2008. p. 13-21.

VILLAS BOAS, Benigna Maria Freitas; SOARES, Sílvia Lúcia. O lugar da avaliação nos espaços de formação de professores. Cadernos CEDES, Campinas, SP, v. 36, n. 99, p. 239-254, ago. 2016. Disponível em: http://www.scielo.br/scielo.php?script=sci_ arttext\&pid=S0101-32622016000200239\&lng=e n\&nrm=iso. Acesso em: maio 2019.

ZEICHNER, Kenneth M. Formação reflexiva de professores: idéias e práticas. Lisboa: Educa, 1993.

ZEICHNER, Kenneth M. Uma análise crítica sobre a "reflexão" como conceito estruturante na formação docente. Educação e Sociedade, Campinas, SP, v. 29, n. 103, p. 535-554, 2008.

Recebido em: 12/05/2019

Aprovado em: 29/07/2019 